\title{
ADOPTION OF SUSTAINABLE INTENSIFICATION PRACTICES AND ITS EFFECT ON SMALLHOLDERS' FOOD SECURITY IN ETHIOPIA
}

\author{
AsERes, M. E. ${ }^{1}-$ LIU, A. $^{2^{*}}-$ MwaluPaso, G. E. ${ }^{1}$ \\ ${ }^{1}$ College of Economics and Management, Nanjing Agricultural University \\ No. 1 Weigang, Nanjing 210095, China \\ ${ }^{2}$ China Center for Food Security Studies, Nanjing Agricultural University, Nanjing, \\ No. 1 Weigang, Nanjing 210095, China \\ (e-mail: A.M.Eshetie-aseresm@yahoo.com, G.E.Mwalupaso-rinscod@gmail.com) \\ *Corresponding author \\ e-mail: liuaj@njau.edu.cn; phone: +86-25-8439-6037 \\ (Received $3^{\text {rd }}$ Feb 2019 ; accepted $29^{\text {th }}$ Mar 2019)
}

\begin{abstract}
Sustainable intensification practice (SIP) facilitates increased and sustained productivity of the limited and existing farmland with less pressure on the environment. Currently, there is a myriad of literature on the effect of SIP on food security. However, unlike previous studies, this study examines the effect of the adoption of multiple sustainable intensification practices on the improvement of food security among smallholder farmers in Ethiopia. Three basic conservation techniques, Agronomic (A), Biological (B) and Physical (P), are analyzed after derivation from 13 implemented soil and water conservation (SWC) practices using principal component analysis (PCA). The result of the multinomial endogenous switching regression (MNESR) shows that SIP adopters have a 55\% higher food security, have $51 \%$ more access to clean water and sanitation, and consume at least one more dietary food item daily than non SIP adopters. A complete $\left(\mathrm{A}_{1} \mathrm{~B}_{1} \mathrm{P}_{1}\right)$ and combined $\left(\mathrm{A}_{0} \mathrm{~B}_{1} \mathrm{P}_{1}\right.$ and $\left.\mathrm{A}_{1} \mathrm{~B}_{1} \mathrm{P}_{0}\right)$ package had the highest food security status as compared to other combination strategies, while single technology users gain the least benefit. Our findings strongly promote the adoption of a complete or combined SIP package in agriculture to leverage the full benefits associated with food security.
\end{abstract}

Keywords: land degradation, packages, environmental protection, SWC, impact

\section{Introduction}

In African dryland agriculture, food security and livelihood of rural households are highly dependent on crop production and livestock farming, which are sensitive to climate-related impacts leading to deforestation and land degradation (Asfaw and Neka, 2017; Kassie et al., 2013; Nkomoki et al., 2018; Wolka et al., 2018). In Sub-Sahara Africa, those whose livelihood and income depend on the most vulnerable agriculture are adversely affected by climate change (Kim et al., 2018). By 2030, the fraction of population living in poverty is expected to reach 122 million (FAO, 2016). Particularly for Ethiopia, the population is expected to reach 160 million by 2050, which is linked to a sizable increase in agricultural production (Josephson et al., 2014). Increasing productivity will be achieved via extensification (expanding farming area) or by intensification (applying technologies in existing areas) (Anderson and Elisabeth, 2015).

Even though food deficiency and income are linked to farm size, $87 \%$ of farming households' in Ethiopia own less than two hectares of cropping land (Anderson and Elisabeth, 2015). Therefore, increasing productivity and securing food demand are prior objectives for adopting new household practice decisions. Rapid population growth and low levels of technology- adopting societies, could contribute to achieving productivity 
increment at the expense of significant environmental risk through cropland expansion (Kassie et al., 2013). Figure 1 presents the trade-off between forest share and arable land expansion due to rural population growth.

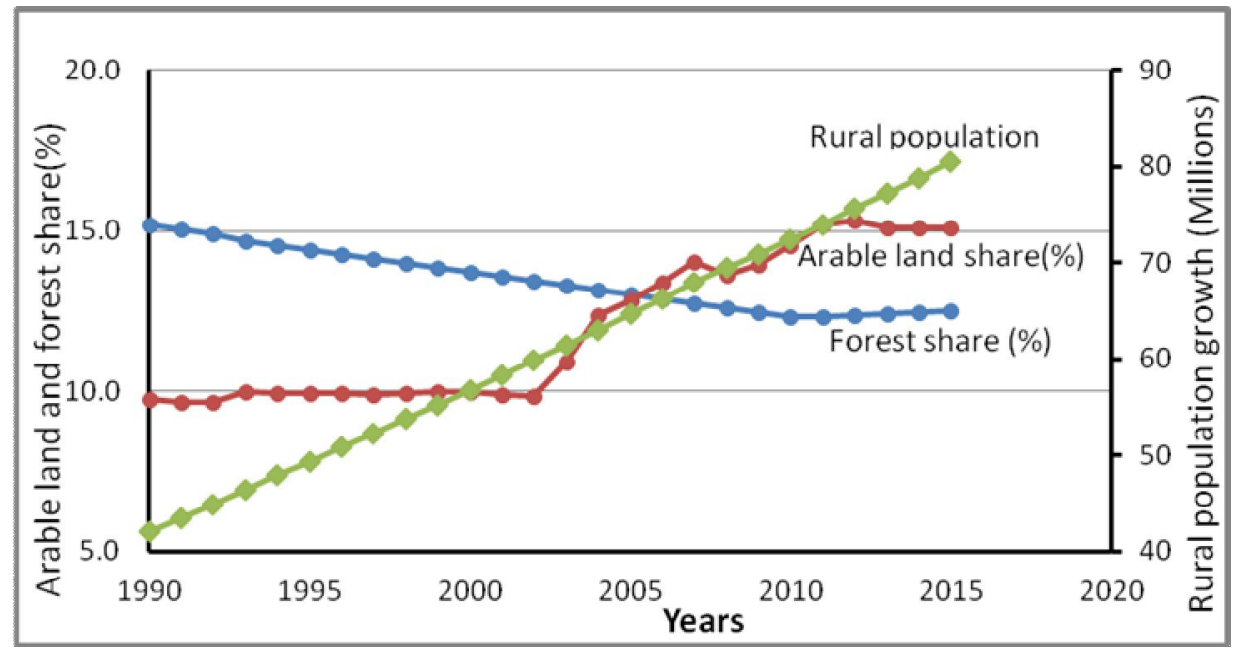

Figure 1. Rural population growth and land use trend in Ethiopia (1990-2015). (Source:

WBdataset, 2018)

Food security and poverty reduction for subsistence farmer strongly correlate with environmental degradation by exploitation of land, forest, and water resources (AbdulRahim et al., 2018; Dejene, 2003). In this context, Ethiopia adopted a Sustainable Intensification Practice (SIP) approach as a new scientific arena for connecting environment and agriculture, which is considered a policy approach for achieving two goals simultaneously (Kassie et al., 2013).

The SIP approach could potentially achieve both economic improvement and environmental protection by maintaining soil fertility and produce higher output in existing cropping areas with less environmental pressure (Kassie et al., 2015a; Kim et al., 2018; Nkomoki et al., 2018). Adopting this strategy improved soil quality and reduced deforestation via climate change mitigation, thereby improving households' nutritional food intake, reducing months of food deficits, as well as food insecurity and poverty (Abdul-Rahim et al., 2018; Kassie et al., 2013, 2015a, b; Nkomoki et al., 2018).

In Ethiopia, farmers adopt different SWC technologies at a given time. Particularly in our chosen study area, more than half of the sampled households (51.04\%) used 4-8 practices in a production season. Considering a single technology's effect on food security analysis will lead to a biased estimation. A review of 160 original field studies by Branca et al. (2013) confirms that isolating the impact of a single practice on productivity or food security is intricate. The author explained that a combined SIP package comprised of agronomy, agroforestry, water harvesting, and conservation techniques contributes to increased yield, as well as reduced soil loss and erosion. Similar studies in Ethiopia (e.g., Coulibaly et al., 2017; Asfaw and Neka, 2017; Wolka et al., 2018) showed similar results. More specifically, Amare et al. (2014) found that in northern Ethiopia, farmers increased their yield by $7 \%$ and reduced soil loss by $68 \%$, by adopting integrated soil bund and grass strips.

Notwithstanding their benefits, land degradation and soil erosion remain very complex and convoluted problems in Ethiopia. A recent SWC government campaign 
mainly focused on the participatory community watershed area conservation and to a much lesser extent on individual plot-farm management. Moreover, SIP package combination and structure technical design are not well understood by farmers.

The objectives of this study are twofold: First, to assess factors that influence the SIP choice by smallholder farmers. Second, estimating the effect of SIP adoption and package choice among adopters on households' food security. We found significant food security improvement for households that practiced complete packages.Also, our study showed better performance in nutritional food consumption and food security status in households that adopted combined agro-biological and biophysical packages compared to those that adopted a single package.

Our paper contributes to the existing literature in four aspects. First, most SIP studies focus on the use of a single practice and related adoption constraints (Branca et al., 2013). However, this paper attempts to link the adoption factors and their impact by considering the many SIPs choice strategy, which is important for development agents focusing on SIP adoption strategies. Second, to the best of our knowledge, the related literature in Ethiopia considered the impact of SIP estimation either in the context of general adoption or package choice approach separately. In this study, we analyzed both cases and found a comprehensive and consistent result. Third, we considered three food security measurement indicators at the same instance which helps to address the dimensions of food availability, access, and utilization, resulting in a robust and consistent estimation. Finally, we employed a systematic model combination where Principal Component Analysis (PCA) was used for variable reduction without losing information from data, while the MNESR model was used to avoid endogeneity and self-selection bias.

\section{Materials and methods}

\section{Description of the study area}

This study was conducted in Benishangul Gumuz National Regional State (BG) in Ethiopia (Fig. 2). It is located in the western part of the country and has three administrative provinces and 21 districts. The Blue Nile River divides the region into two main parts, the northern part Metekel province, and southern part Assosa and Kemashi provinces. The region is endowed with water sources such as Beles, Dhidhsa, Dinder and Dabus rivers all of which are a tributary of Abay (Blue Nile) river. From the total estimated area to about 5,069,900 ha of the region, the arable land accounts about 911,877 ha and 24.4\% of this land has potential for irrigation (Emana, 2010; Teklemariam et al., 2016); and forest land is estimated to be 3,963,750 ha (WBISPP, 2005).

The three major agro-climatic zones of the region are (i) low land or Kola (about $75 \%$ of the region), (ii) Midland or Woynadega (accounts 24\%), and (iii) Highland or Dega agro-climatic zone about $1 \%$ of the region (Teklemariam et al., 2016). The mean annual rainfall of the region is between 860 and $1275 \mathrm{~mm}$, and the temperature varies with a daily maximum of $20-25^{\circ} \mathrm{C}$ in the rainy season and rises to $35-40{ }^{\circ} \mathrm{C}$ in the dry season.

According to 2007 CSA (Central Statistics Agency) population census report, the region had a total population of 670,847 with $3 \%$ annual growth rate which is higher than the national growth rate of $2.6 \%$ per annum. Field crops including maize, sorghum, finger millet, okra, soybean, haricot bean, sesame, and groundnut are majorly produced 
in seven districts of the study area. The region recently experienced environmental degradation resulting to severe soil erosion, long dry season, erratic rainfall, and loss of soil fertility. Migration and resettlement programmes is the main cause of deforestation and cropland expansion. For example, in Sirba Abay district, between 1987 and 1998, the cultivable land expanded by 100\% and between 1998 and 2007, the expansion was tripled (300\%). Petteri Vuorinen (2016) in four districts confirmed that $74 \%$ of the forest were cleared due to cropland expansion, whereas $11 \%$ was done for fuelwood/charcoal as an income source, and 6\% attributed for investment purpose. This evidently indicates that agricultural land expansion effect takes a lion-share for environmental degradation that is aimed to increase productivity and smallholders food provision (Petteri Vuorinen, 2016).

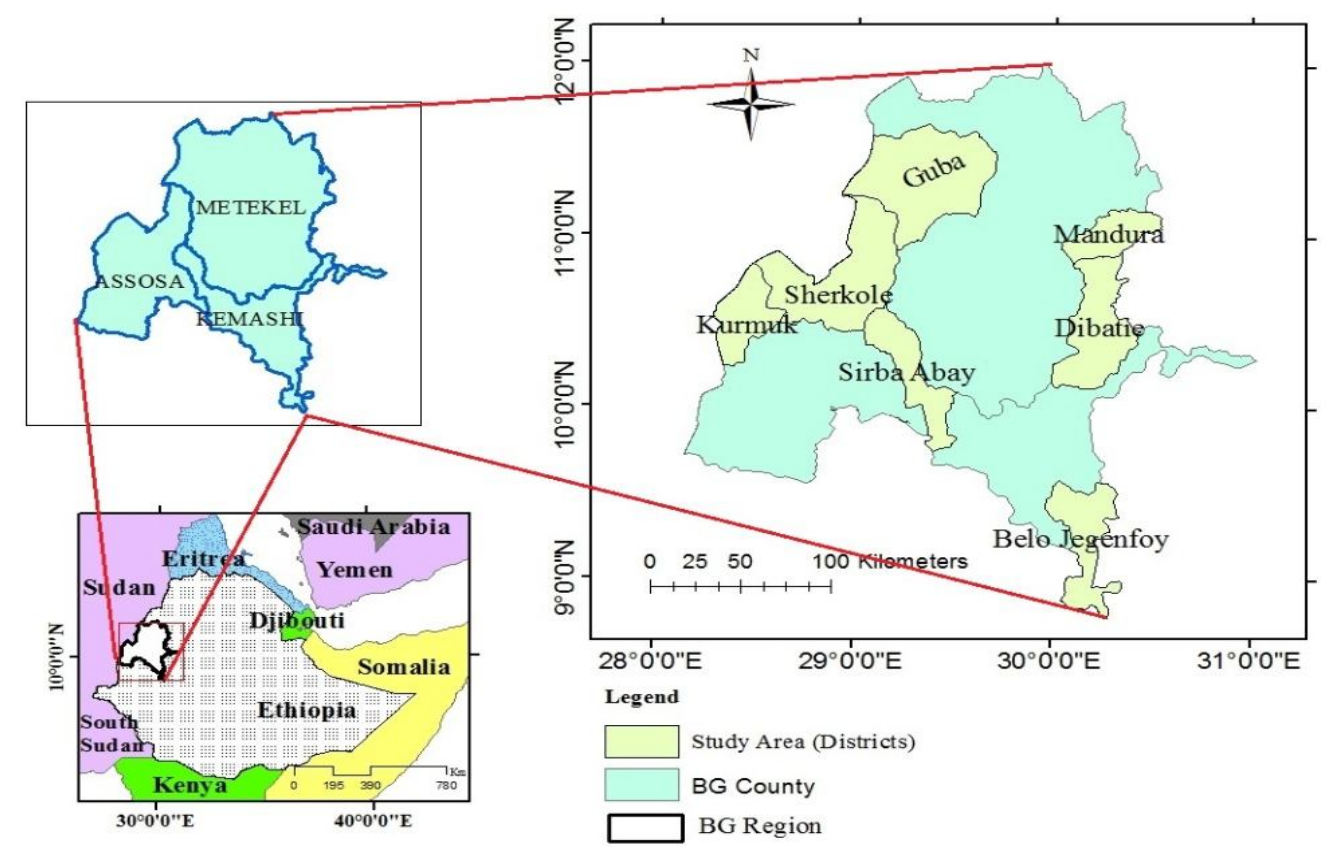

Figure 2. Study area location

\section{Data source}

We employed a two-stage sampling technique to select respondents, In the first stage, 7 out of 21 districts were purposively selected. The selection was based on regional government, development of stakeholders intervention, and strong SWC campaign. Population size within the seven districts accounted for $27 \%(179,313)$ of the total regional population (Emana, 2010). Furthermore, people from neighboring regions also migrated to this area as seasonal and contract farming actors.

In stage two, 30 peasant associations (PAs) from all seven districts were purposively selected. During PA (village) selection, the landscape condition, soil quality, vegetation cover, erosion incidence; SWC practice, farming trends, and experience; and area productivity were taken into consideration. Finally, a simple random sampling technique was employed to select 909 respondents (heads of household) from the PAs (Table 1). Trained enumerators interviewed the sampled household heads using a pretested and structured questionnaire with supervision of the extension officer. 
Prior to conducting the farmer interviews, various key informants and focus group discussions were held on institutional (56 agriculture office experts at a different level), community, and district levels (132 model farmers and community elders). Data on household SIP adoption and food security impact estimation were collected in 2016 using a one-year recall questionnaire. We consider two reference periods of different production seasons: For SIP adoption, the reference period was March 2014 to February 2015, whereas for food security and production, information was gathered from March 2015 to February 2016.

Table 1. Sampled household heads by district and adoption frequency $(N=909)$

\begin{tabular}{|c|c|c|c|c|c|c|c|}
\hline \multirow{2}{*}{ No. } & \multirow{2}{*}{ Districts } & \multicolumn{2}{|c|}{ Adopters } & \multicolumn{2}{|c|}{ Non-adopters } & \multicolumn{2}{|c|}{ Pooled sampled } \\
\hline & & Frequency & $\%$ & Frequency & $\%$ & Frequency & $\%$ \\
\hline 1 & Belojiganfoy & 86 & 11.21 & 24 & 16.90 & 110 & 12.1 \\
\hline 2 & Debati & 56 & 7.30 & 3 & 2.11 & 59 & 6.49 \\
\hline 3 & Guba & 19 & 2.48 & 14 & 9.86 & 33 & 3.63 \\
\hline 4 & Kurmuk & 90 & 11.73 & 13 & 9.15 & 103 & 11.33 \\
\hline 5 & Mandura & 247 & 32.20 & 25 & 17.61 & 272 & 29.92 \\
\hline 6 & Sherkole & 246 & 32.07 & 21 & 14.79 & 267 & 29.37 \\
\hline \multirow[t]{2}{*}{7} & Sirbabay & 23 & 3.00 & 42 & 29.58 & 65 & 7.15 \\
\hline & Total & 767 & $84.4 \%$ & 142 & $15.6 \%$ & 909 & 100.00 \\
\hline
\end{tabular}

\section{Variable description}

\section{Food security measurement}

Measuring food (in)security is quite complex, where household behaviors and dimension aspect should be considered. Food security entails multiple aspects, and it is therefore not easy to capture the full range of dimensions relating to food availability, access, and safety of a household or individual from a single measurement (Mabiso et al., 2014). Again, there is no a separate best measurement metric; and using multiple indicators is recommended by Maxwell et al. (2014) and Mabiso et al. (2014).

In this paper, we estimated household food security status using three different indicators as described below. These multiple indicators provide robust estimation for the evaluation's consistency and comparability purposes. Table 2 presents the definition and summary statistics for all variables.

\section{Dependent variables}

\section{Household dietary diversity score (HDDS)}

Household dietary diversity (HDD) is used to compute a household's access to nutritional food and energy intake within 24-hours consumption recall period (Ecker, 2018; Maxwell et al., 2014; McDonald et al., 2015; Moroda et al., 2018; PérezEscamilla et al., 2017). The number of consumable food groups range from 0 to 12 point scale. In this study, they include cereals; and pulse; vegetable with tuber; root and tubers; leafy vegetable; fruits, egg; meat, poultry; fish; milk and milk products; honey and sugar; and oil and condiments. All the food groups have equal value of one, and the total score value is calculated as a whole food list consumed by the family during the last $24 \mathrm{~h}$. 


\section{Self-assessed measures of food security (SAFS)}

Self-assessment of a household on their food security status examines the change in food availability (shortage or surplus) during the past 12 months (January to December 2016). SAFS used to measure the household's access to enough food. Since SAFS estimation is subjective and constructed from a single question, one might expect this indicator to be less reliable. However, Shiferaw et al. (2014) and Maxwell et al. (2014) from Ethiopia applied it as an indicator to estimate food security. The response was recorded as 1 if the household had no food shortage throughout the year and, zero otherwise.

\section{Access to water availability, sanitation, and hygiene (WASH)}

The food security outcome is not only determined by food-related constraints of a household, but also by non-food causes that affect its status. WASH is used to estimate the food utilization dimension of food security as an additional parameter. PinstrupAndersen (2009) and Moroda et al. (2018) suggested a consideration of the non-food factors like access to clean water and sanitation factors. The households' self-response is recorded as a dummy variable 1 if $\mathrm{HH}$ had access to WASH, and 0 otherwise.

\section{Key independent variables}

Sustainable intensification practice (SIP) adoption and package choice

To maximize productivity through improving and conserving soil and water resource, farmers are more likely to practice multiple SWC techniques (Kassie et al., 2013). Thirteen SWC practices were reduced and categorized into three main groups Agronomic (A), Biological (B) and Physical (P) conservation practices. We define SIP adoption as a dummy, where 1 denotes a household that practiced at least one of the three categories, and 0 otherwise.

On the other hand, three SIP categories generate six probability combinations (Table 5). The first SIP choice was adopting a complete SIP- $\mathrm{A}_{1} \mathrm{~B}_{1} \mathrm{P}_{1}$ (AgronomicBiological-Physical) package. However, not all farmers practice full SWC techniques, except for innovative and model farmers who may implement many practices at once in a single production season. Adopting a complete package has short-term benefits such as augmented productivity, income, and fodder (Amare et al., 2014; Wolka et al., 2018). The second SIP choice was the $\mathrm{A}_{1} \mathrm{~B}_{1} \mathrm{P}_{0}$ (Agronomic-Biological) package that required less technical skill and knowledge. For example, multipurpose trees and grass strips integrated with agronomic practice aided in nutrient recycling for crops, soil fertility improvement, and water-holding capacity enhancement. The third SIP choice considered was the $\mathrm{A}_{0} \mathrm{~B}_{1} \mathrm{P}_{1}$ (biophysical) package, which was adopted mainly to support physical structures with grass strips.

Farmers are less likely to practice physical structure alone due to area share from cropping and the higher frequency of repairs. Amare et al. (2014) confirm that the combined bio-physical technique has a substantial effect on runoff reduction and soil loss compared to other treatments.

The fourth SIP choice was the $\mathrm{A}_{1} \mathrm{~B}_{0} \mathrm{P}_{1}$ (Agronomic-Physical) combination. Farmers built physical structures when the plot area was gentle or sloppy to minimize the run-off velocity and conserve soil and water. The fifth SIP single package choice was the $\mathrm{A}_{0} \mathrm{~B}_{1} \mathrm{P}_{0}$ (Biological) conservation method, which has a dual benefit of conserving and 
recycling soil nutrients and generating income from plants (fodder, fuelwood, and wood product). Our final consideration was the agronomic practice choice $\mathrm{A}_{1} \mathrm{~B}_{0} \mathrm{P}_{0}$. Usually, it is assumed that farmers practice at least one measure of the soil fertility improvement techniques as a coping strategy to reduce production risk.

Table 2. Variable definition and descriptive statistics

\begin{tabular}{|c|c|c|c|}
\hline Variables & Description & Mean & Std dev \\
\hline \multicolumn{4}{|l|}{ Outcome variable } \\
\hline HDD & Household dietary diversity score & 5.81 & 2.25 \\
\hline Food secure (SAFS) & Does HH have enough food in the last year? $($ yes $=1$ ) & 0.53 & 0.50 \\
\hline Water $\&$ sanit access & Household water and sanitation accessibility $($ yes $=1)$ & 0.47 & 0.50 \\
\hline \multicolumn{4}{|l|}{ Intervention variable } \\
\hline SIPs adoption (dummy) & $\begin{array}{l}\text { Head of HH who adopt sustainable intensification } \\
\text { practice ( } 1=\text { adopter })\end{array}$ & 0.84 & 0.37 \\
\hline $\mathrm{A} 0 \mathrm{~B} 0 \mathrm{P} 0$ & Head of HH who do not adopt any SIP practice & 0.16 & \\
\hline A0B0P1 & Head of HH who adopts physical structure package & 0.01 & \\
\hline A0B1P1 & Head of HH who adopts a biophysical package & 0.12 & \\
\hline A1B1P1 & Head of HH who adopts all SIPs package & 0.37 & \\
\hline A1B1P0 & Head of HH who adopts an agro-biological package & 0.15 & \\
\hline A1B0P0 & Head of HH who adopts the agronomic practice & 0.06 & \\
\hline $\mathrm{A} 0 \mathrm{~B} 1 \mathrm{P} 0$ & Head of HH who adopts the biological practice & 0.04 & \\
\hline A1B0P1 & Head of HH who adopts the agro-physical practice & 0.11 & \\
\hline \multicolumn{4}{|l|}{ Explanatory variable } \\
\hline HH education & Household head have formal education $($ yes $=1)$ & 0.72 & \\
\hline Gender & Sex of the head of a household $(1=$ male $)$ & 0.85 & \\
\hline Family size (AEU) & Family size in adult equivalent unit (AEU) & 6.26 & 2.63 \\
\hline Cropping area & Household owned Farm size (ha) & 1.89 & 0.91 \\
\hline Livestock asset (TLU) & livestock asset in tropical livestock unit (TLU) & 2.16 & 2.90 \\
\hline Crop income & Annual household crop income in ETB & 16069.11 & 16538.38 \\
\hline Off-farm participate & household participated in off-farm income activity & 0.56 & \\
\hline Extension access & Household have access to extension service & 0.72 & 0.45 \\
\hline Market access & Household have access to input $\&$ output market & 0.65 & 0.48 \\
\hline Main road access & household who have road access $($ yes $=1)$ & 0.70 & 0.46 \\
\hline Access to credit & $1=$ if a household has access to credit service & 0.44 & \\
\hline Group membership & $1=$ if the household is a member of a rural social network & 0.61 & 0.49 \\
\hline $\mathrm{HH}$ trained on SWC & $1=$ if $\mathrm{HH}$ trained on soil and water conservation & 0.64 & \\
\hline HH trained on SNRM & $\begin{array}{c}1=\text { if } \mathrm{HH} \text { trained on sustainable natural resource } \\
\text { management }\end{array}$ & 0.60 & \\
\hline \multicolumn{2}{|r|}{ Total } & 909 & \\
\hline
\end{tabular}

Table 4 presents the identified SIP measures and their grouping categories. We consider agronomic package adoption $\left(\mathrm{A}_{1}\right)$, if a household head practices at least two techniques from an agronomic; for Biological $\left(B_{1}\right)$ at least one from the biological method; and if $\mathrm{HH}$ adopts at least one from four structural measures, we assign as physical practice adopter $\left(\mathrm{P}_{1}\right)$. Finally, the causal effect of SIP adoption on food security 
was estimated in overall (SIP adoption dummy) and unconditional probabilities (six possible combinations) method.

The choice of the explanatory variable was based on related smallholders SIP adoption decision and economic welfare effect study literature and presented in Table 2 (Amare et al., 2014; Kassie et al., 2013, 2015a, b; Kpadonou et al., 2017; Nkomoki et al., 2018; Wekesa et al., 2018).

\section{Econometrics approach}

In many developing countries including Ethiopia, input and output market imperfection and high seasonality are common constraints for smallholder farmers. Also, high fluctuation and volatility nature of food and agricultural input price strongly correlates to the availability of food. Therefore, the adoption intensity and willingness to invest for newly introduced practice is dependent on net benefit gained from the process. The farm household adjusts adoption behavior for readily available technologies by looking for the opportunity. If the utility from a new method is higher than the conventional system, a farmer will decide to adopt. Farmers want to maximize their income by choosing the optimal combination of SIP package.

Unlike experimental studies, the selection of adoption and non-adoption in crosssectional survey research was not randomized, and observable and unobservable characteristics profoundly influence the decisions. It implies that farmers in the research area were not equally exposed to the new technology. In causal effect analysis, both controlled and treatment groups must have similar behaviors to avoid a biased estimation. As a result, we employed a new two-stage selection-bias correction approach of the multinomial endogenous switching regression (MNLESR) (Bourguignon et al., 2007) to determine the real effects of farmers choice of SIP package and the outcome equation. Use of MNLESR model has a triple advantages. First, it helps to address biasness that arises from the unobservable variable. Second, the model allows getting consistent and efficient estimates of the adoption process with reasonable correction for the outcome equation. Third, it assists in computing the impacts of both separate and combined practice simultaneously (Abdulai and Huffman, 2014; Coulibaly et al., 2017; Kassie et al., 2015b; Wekesa et al., 2018).

\section{Multinomial adoption selection model (MNL)}

In the first stage, we used a multinomial logit model (MLM) to examine the factors that affect a farmers SIP packages choice. Farmers have six mutually exclusive $(P)$ alternative SIP strategies and will adapt by comparing its effect to maximize their utility. Consider $I_{i j}^{*}$ is a latent variable that represents the $j$ th farmers behavior in practicing SIP combinations $i(i=1, \ldots 6)$ and expressed as follows $(E q .1)$ :

$$
I_{i j}^{*}=X_{i j} \beta_{j}+\varepsilon_{i j}
$$

where $\mathrm{X}_{\mathrm{ij}}$ captures vector observed exogenous variable (household characteristics, farm, and asset characteristics, institutional features, and knowledge and extension access variable), while $s_{i j}$ are the error term from an observed characteristics.

From available mutually exclusive SIP $p$ combinations of packages, a farmer will choose ith SIPs combination if: 


$$
\mathrm{I}=\left\{\begin{aligned}
1 \text { if } I_{i j}^{*}>\max _{p \neq 1} & \left(I_{p j}^{*}\right) \text { or } \omega_{1 j}<0 \\
& \cdot \\
& \cdot \\
\text { i if } I_{i j}^{*}>\max _{p \neq 1}\left(I_{p j}^{*}\right) \text { or } \omega_{i j}<0 & \text { for all } p \neq 1 .
\end{aligned}\right.
$$

According to Equation 2, the ith will adopt ith package to maximize utility, if

$$
\max _{p \neq i}\left(I_{p j}^{*}-I_{H}^{*}\right)<0
$$

Since we are assuming $\varepsilon_{i j}$ as the error term from an observed characteristics and to be identically Gumbel distributed and independent, Equation 2 leads to the multinomial logit model of the probability that farmers will choose combinations (pij) as shown in Equation 3:

$$
p i j=\operatorname{pr}\left(\omega_{i j}<0 X_{i j}\right)=\frac{\exp \left(x_{i j} \beta_{j}\right)}{\sum_{p \neq 1}^{i} \exp \left(x_{i j} \beta_{p}\right)}
$$

\section{Multinomial endogenous switching regression estimation}

Following similar impact studies of Abdulai and Huffman (2014), Kassie et al. (2015b), Coulibaly et al. (2017) and Wekesa et al. (2018), we applied a multinomial endogenous switching regression model which is developed by Lee (1982) to estimate the SIP adoption causal effect.

An endogenous switching regression model of a selection bias correction framework used to estimate the farmers SIP adoption impact of each strategy on household food security through multiple indicators. The $A_{0} B_{0} B_{0}$ SIPs package was taken as the base category (non-responsive) and denoted as $i=1$ and the adopter practiced at least one from remaining SIP $(i=2,3,4,5,6)$ combination package. The food security status implication for each regime is described as Equation 4:

$$
\left\{\begin{array}{cc}
\text { Regime 1: } \Omega_{i 1}={ }_{i} \alpha_{1}+v_{i 1} & \text { if } i=1 \\
\cdot & \\
\cdot & \\
\text { Regime } i: \Omega_{i j}={ }_{i} \alpha_{j}+v_{i j} & \text { if } i=j
\end{array} \quad(i=2,3,4,5,6)\right.
$$

where $\Omega_{i j}$ denoted the $i$ th farmers food security status in regime $\mathbb{1}$ combination, $i$ is for the set of exogenous variable (household characteristics, farm, and asset characteristics, institutional features, and knowledge and extension access variable) and the error term denoted by $v_{i j}$ that capture the uncertainty and distributed with $E\left(v_{i j}\right)=0$ and $\operatorname{var}\left(v_{i j}\right)=\sigma_{j}^{2}$. If the error term $v_{i j}$ and $\varepsilon_{i j}$ are not independent a consistent estimation of $a_{j}$ requires to avoid biased and the inclusion of the selection correction term of alternative choice in Equation 4. Then based on Bourguignon et al. (2007) suggestion we can estimate $v_{i j}$ and $\varepsilon_{i j}$ consistently with Equation 4 by MESR model developed by Lee (1982) and specified as in Equation 5: 


$$
\left\{\begin{array}{cc}
\text { Regime 1: } \Omega_{i 1}={ }_{i} \alpha_{1}+\sigma_{11}+e_{i 1} \quad \text { if } i=1 \\
\cdot \\
\cdot \\
\text { Regime } i: \Omega_{i j}={ }_{i} \alpha_{j}+\sigma_{j j}+e_{i j} \quad \text { if } i=j,
\end{array}\right.
$$

where $e_{i j}$ is the error term and $\sigma_{j}$ is also the covariance between $\varepsilon^{\prime} s$ and $v^{\prime} s$, while ${ }_{i}$ is the inverse Mills ratio from the estimated probabilities.

Following (Di Falco et al., 2011), ESR can be used to examine the average treatment effect on the treated (ATT) and by comparing the expected outcome of the food security status of adopters with and without adoption of SIP combination packages in the actual and counterfactual scenario presented and defined in Equation 6:

$$
A T T=E\left(\Omega_{i j} \mid i=j\right)-E\left(\Omega_{i 1} \mid i=j\right)={ }_{i}\left(\alpha_{j}-\alpha_{1}\right)+i\left(\sigma_{j}-\sigma_{1}\right)
$$

\section{Results and discussion}

\section{Descriptive statistics}

\section{A household intensity of SIP adoption estimation}

Under dry land economy, as in the case of Ethiopia, farmers adopt multiple SWC technologies aimed at increasing productivity and reducing the risk of food deficiency (Kpadonou et al., 2017). Table 3 presents the households' SIP adoption intensity, which ranges from zero to eleven SWC measures. Households are selective, and have different SIP adoption intensities (Wolka et al., 2018). While some farmers practice up to 11 SWC techniques, $15.62 \%$ (142 HHs) do not implement any of the 13 practices. However, from the sampled heads of HHs, 84.38\% adopted at least one sustainable intensification technology in their cropping area.

Table 3. Heads of households adoption intensity on SIP package

\begin{tabular}{c|c|c|c}
\hline Number of practice & Frequency & Adopters (\%) & Cumulative \\
\hline Heads of HHs who did not practice any SIP $(0)$ & 142 & 15.62 & 15.62 \\
Heads of HHs who practice 1 & 29 & 3.19 & 18.81 \\
2 & 48 & 5.28 & 24.09 \\
3 & 128 & 14.08 & 38.17 \\
4 & 119 & 13.09 & 51.27 \\
5 & 125 & 13.75 & 65.02 \\
6 & 91 & 10.01 & 75.03 \\
7 & 74 & 8.14 & 83.17 \\
8 & 55 & 6.05 & 89.22 \\
9 & 51 & 5.61 & 94.83 \\
10 & 32 & 3.52 & 98.35 \\
11 & 15 & 1.65 & 100.00 \\
12 & 0.00 & 0.00 & 100.00 \\
13 & 0.00 & 0.00 & 100.00 \\
\hline Total & 909 & 100.00 & \\
\hline
\end{tabular}


More than half of the sampled households (51.04\%) used 4-8 practices, $22.55 \%$ used 1-3 practices and a few (10.78\%) used $>8$ SIP technologies. The adoption intensity descriptive results showed that in the study area, most households experienced at least one practice from each SWC category (Agronomic, Biological and Physical measures), and entirely adopted more than three technologies.

\section{SIP variable reduction and grouping strategy}

Table 4 presents the reduced form of linear combination loadings estimation results from multiple on-farm level SIP practices. Following suggestions by Goswami et al. (2012) and Chatterjee et al. (2015), the orthogonal rotation was executed on principal components, and four principal components with eigenvalue $>1$ were considered. From the overall data variability, $61.03 \%$ is explained by four components. The first component (hereafter called agronomic practice) had a positive effect on loadings and explained $20.11 \%$ of the variance from total PC variability.

Principal components $2-4$ accounted for 15.6 , 14.04, and $11.29 \%$ of the loadings, respectively. The second principal component group is hereafter named as biological practice. In this study, the third most determinant component group was associated with a farmers participation in physical structure practices. The fourth principal component included one physical element (employing check dum) and an agronomic element (strip mulching) which was inconsistent with SWC groupings (Abdul-Rahim et al., 2018). We, therefore, excluded component 4 to harmonize SIP groupings. Whether component 4 affects the impact analysis requires further investigation. Therefore, for this study, three component loading variables had more importance in explaining SIP adoption and variance of effect analysis. According to Kaiser (1958), an average communality above 0.60 is the minimum criteria for PCA analysis, which was met in our study $61.03 \%$. This shows that our PCA estimation is a good fit, with good data quality.

Table 4. Rotated components loading (greater than 0.3)

\begin{tabular}{c|c|c|c|c|c}
\hline Strategy & Comp1 & Comp2 & Comp3 & Comp4 & Unexplained \\
\hline Apply soil bund & & & 0.6265 & & 0.3095 \\
Apply check dam & & & & 0.3059 & 0.5784 \\
Use cut-off drain & & & 0.4449 & & 0.4649 \\
Apply micro-basin & & & 0.4630 & & 0.396 \\
Use organic fertilizer & 0.5229 & & & & 0.3014 \\
Use conservation agriculture & 0.3048 & & & & 0.4779 \\
Apply crop rotation & 0.5039 & & & & 0.3812 \\
Apply shifting cultivation & 0.5162 & & & & 0.2835 \\
Apply strip mulching & & & & 0.4356 & 0.4537 \\
Apply terrace & & & 0.7316 & & 0.3113 \\
Planting grass strips & & 0.3992 & & & 0.5036 \\
A forestation of fields & & 0.6271 & & & 0.2917 \\
Apply agroforestry & & 0.5243 & & & 0.3125 \\
Eigenvalue & 2.6148 & 2.0270 & 1.8248 & 1.4678 & \\
Eigenvalues \% contribution & 20.11 & 15.59 & 14.04 & 11.29 & \\
Cumulative \% & 20.11 & 35.71 & 49.74 & 61.03 & \\
\hline
\end{tabular}

Comp1 denotes agronomic practices (A), Comp2 for biological (B) and Comp3 for physical (P) 


\section{A household probability for SIP choice description}

After considering varimax rotation from high factor loadings, household choice to different SIP packages (combinations) was estimated. Table 5 presents the different possible combination of packages chosen by households referring to non-adopters $\mathrm{A}_{0} \mathrm{~B}_{0} \mathrm{P}_{0}(15.62 \%)$ as a base. The study discussed six out of eight SIP probabilities.

Table 5. Alternative sustainable intensification practices (SIPS) package probabilities

\begin{tabular}{|c|c|c|c|c|c|c|c|c|c|}
\hline \multirow{2}{*}{$\begin{array}{c}\text { Choice } \\
\text { (ith) }\end{array}$} & \multirow{2}{*}{ Combination } & \multicolumn{2}{|c|}{$\mathbf{A}=$ agronomic } & \multicolumn{2}{|c|}{$\mathrm{B}=$ biological } & \multicolumn{2}{|c|}{$\mathbf{P}=$ physical } & \multirow{2}{*}{ Frequency } & \multirow{2}{*}{ Percentage } \\
\hline & & $\mathbf{A}_{1}$ & $\mathbf{A}_{0}$ & $\mathbf{B}_{1}$ & $\mathbf{B}_{0}$ & $\mathbf{P}_{1}$ & $\mathbf{P}_{\mathbf{0}}$ & & \\
\hline 1 & $\mathrm{~A}_{0} \mathrm{~B}_{0} \mathrm{P}_{0}$ & \multirow[b]{4}{*}{$\checkmark$} & $\checkmark$ & \multirow[b]{3}{*}{$\checkmark$} & $\checkmark$ & \multirow[b]{2}{*}{$\checkmark$} & \multirow[t]{2}{*}{$\checkmark$} & 142 & 15.62 \\
\hline 2 & $\mathrm{~A}_{0} \mathrm{~B}_{0} \mathrm{P}_{1}$ & & $\checkmark$ & & $\checkmark$ & & & 6 & 0.70 \\
\hline 3 & $\mathrm{~A}_{0} \mathrm{~B}_{1} \mathrm{P}_{1}$ & & $\checkmark$ & & & $\checkmark$ & & 111 & 12.20 \\
\hline 4 & $\mathrm{~A}_{1} \mathrm{~B}_{1} \mathrm{P}_{1}$ & & & $\checkmark$ & & $\checkmark$ & & 336 & 36.96 \\
\hline 5 & $\mathrm{~A}_{1} \mathrm{~B}_{1} \mathrm{P}_{0}$ & $\checkmark$ & & $\checkmark$ & & \multirow[b]{4}{*}{$\checkmark$} & $\checkmark$ & 132 & 14.52 \\
\hline 6 & $\mathrm{~A}_{1} \mathrm{~B}_{0} \mathrm{P}_{0}$ & $\checkmark$ & \multirow{3}{*}{$\checkmark$} & \multirow{3}{*}{$\checkmark$} & $\checkmark$ & & $\checkmark$ & 50 & 5.50 \\
\hline 7 & $\mathrm{~A}_{0} \mathrm{~B}_{1} \mathrm{P}_{0}$ & & & & & & $\checkmark$ & 32 & 3.50 \\
\hline 8 & $\mathrm{~A}_{1} \mathrm{~B}_{0} \mathrm{P}_{1}$ & $\checkmark$ & & & $\checkmark$ & & & 100 & 11.00 \\
\hline \multicolumn{8}{|c|}{ Total } & 909 & 100 \\
\hline
\end{tabular}

$\mathrm{A}_{1}=$ agronomic users, $\mathrm{A}_{0}=$ non-users of agronomic and others have a similar interpretation

The farmer had a chance to choose from the set of six mutually exclusive combinations during a production season. Approximately $14.52 \%$ of the farmers applied Agro-Biological methods $\left(\mathrm{A}_{1} \mathrm{~B}_{1} \mathrm{P}_{0}\right)$, while $12.2 \%$ applied the biophysical conservation package $\left(\mathrm{A}_{0} \mathrm{~B}_{1} \mathrm{P}_{1}\right)$.

Other farmers used packages $\mathrm{A}_{1} \mathrm{~B}_{0} \mathrm{P}_{1}, \mathrm{~A}_{1} \mathrm{~B}_{0} \mathrm{P}_{0}$, and $\mathrm{A}_{0} \mathrm{~B}_{1} \mathrm{P}_{0}$. Overall the majority of the farmers $(37 \%)$ applied a complete SIP package $\left(\mathrm{A}_{1} \mathrm{~B}_{1} \mathrm{P}_{1}\right)$. This observation concurs with other studies such as (Kipkoech Anderson et al., 2015; Wekesa et al., 2018).

\section{Empirical result}

\section{Determinants of SIP adoption choices}

The objective of this study dwelt on the SIP adoption constraints and their impact on households' food security. In the first stage, we used the Multinomial logit (MNL) model to describe SIP packages adoption decision and possible constraints by considering non SIP users $\left(\mathrm{A}_{0} \mathrm{~B}_{0} \mathrm{P}_{0}\right)$ as the base. The result of this estimation is essential for identifying factors that affect SIP package combination adoption and suggesting possible adoption constraints to development partners and policymakers. A unit change in an explanatory variable and its variation on the probability of particular choices was estimated by the MNL marginal effect model and is reported in Table 6. The Wald test estimation result of the regression coefficient was jointly equal to zero (Wald $\operatorname{ch}^{2}(91)=$ $918.10 ; p=0.000)$. Farmers who only adopted the physical structure were not discussed due to the mundane representation of this group. The marginal effect estimation result confirmed that the explanatory variable coefficients varied substantially across the alternative packages.

Among the household characteristics, male household heads positively associated with agronomic $\left(\mathrm{A}_{1} \mathrm{~B}_{0} \mathrm{P}_{0}\right)$ and biological $\left(\mathrm{A}_{0} \mathrm{~B}_{1} \mathrm{P}_{0}\right)$, but negatively associated with laborintensive Agro-Physical $\left(\mathrm{A}_{1} \mathrm{~B}_{0} \mathrm{P}_{1}\right)$ packages. The results were in agreement with data 
from Asfaw and Neka (2017) and Tiwari et al. (2008). However, having the formal education of a household head reduced the probability of adopting agronomic $\left(\mathrm{A}_{1} \mathrm{~B}_{0} \mathrm{P}_{0}\right)$ practice by $4.6 \%$. This could be due to the fact that education is necessary for adopting the knowledge-intensive physical structure compared to the agronomic practice. Kpadonou et al. (2017) also observed a negative correlation between formal education and mulching and sustainable agricultural practices (SAP) adoption.

Table 6. Marginal effect based on SIP choice

\begin{tabular}{|c|c|c|c|c|c|c|}
\hline Variables & $\begin{array}{c}A_{1} B_{1} P_{0} \\
d y / d x\end{array}$ & $\begin{array}{c}A_{0} B_{1} P_{1} \\
d y / d x\end{array}$ & $\begin{array}{c}A_{1} B_{1} P_{1} \\
d y / d x\end{array}$ & $\begin{array}{c}\mathbf{A}_{1} \mathbf{B}_{0} \mathbf{P}_{0} \\
\mathbf{d y} / \mathbf{d x}\end{array}$ & $\begin{array}{c}\mathbf{A}_{0} \mathbf{B}_{1} \mathbf{P}_{0} \\
\mathbf{d y} / \mathbf{d x}\end{array}$ & $\begin{array}{c}\mathbf{A}_{1} \mathbf{B}_{0} \mathbf{P}_{1} \\
\mathbf{d y} / \mathbf{d x}\end{array}$ \\
\hline \multirow[t]{2}{*}{ Gender } & 0.0408 & -0.0510 & 0.0292 & $0.0452^{* *}$ & $0.0264^{*}$ & $-0.1086^{* *}$ \\
\hline & 0.0387 & 0.0491 & 0.0568 & 0.0197 & 0.0156 & 0.0468 \\
\hline \multirow[t]{2}{*}{ HH education } & -0.0103 & 0.0216 & 0.0256 & $-0.0464^{*}$ & 0.0035 & 0.0386 \\
\hline & 0.0367 & 0.0385 & 0.0482 & 0.0273 & 0.0176 & 0.0278 \\
\hline \multirow[t]{2}{*}{ Family size } & -0.0037 & 0.0096 & -0.0062 & -0.0037 & -0.0006 & -0.0028 \\
\hline & 0.0065 & 0.0072 & 0.0086 & 0.0046 & 0.0036 & 0.0059 \\
\hline \multirow[t]{2}{*}{ Cropping area } & -0.0088 & -0.0245 & 0.0302 & -0.0007 & -0.0064 & $0.0402^{* * *}$ \\
\hline & 0.02 & 0.0224 & 0.0253 & 0.0127 & 0.0101 & 0.0156 \\
\hline \multirow[t]{2}{*}{ Log-crop-Inc } & $-0.1204^{* * *}$ & $-0.0829^{* * *}$ & $0.4342^{* * *}$ & $-0.0473^{* * *}$ & $-0.0454^{* * *}$ & $-0.0827^{* * *}$ \\
\hline & 0.0242 & 0.0264 & 0.0339 & 0.0154 & 0.0117 & 0.0193 \\
\hline \multirow[t]{2}{*}{ Off-farm partici } & 0.0187 & $0.0610^{*}$ & 0.0286 & 0.0049 & 0.0036 & $-0.1445^{* * *}$ \\
\hline & 0.0335 & 0.0356 & 0.0444 & 0.0207 & 0.0162 & 0.0305 \\
\hline \multirow[t]{2}{*}{ Exten-access } & $0.0721^{* *}$ & -0.0160 & 0.0411 & -0.0153 & -0.0008 & -0.0365 \\
\hline & 0.0345 & 0.0436 & 0.0546 & 0.0252 & 0.0180 & 0.0335 \\
\hline \multirow[t]{2}{*}{ Market access } & -0.002 & 0.0366 & 0.0104 & -0.0423 & -0.0110 & 0.0140 \\
\hline & 0.0368 & 0.0388 & 0.0502 & 0.0264 & 0.0184 & 0.0294 \\
\hline \multirow[t]{2}{*}{ Road access } & 0.0016 & 0.0401 & -0.0696 & -0.0007 & -0.0119 & $0.0959^{* * *}$ \\
\hline & 0.0386 & 0.0399 & 0.0525 & 0.0227 & 0.0194 & 0.0253 \\
\hline \multirow[t]{2}{*}{ Credit access } & $0.2218^{* * *}$ & $-0.0608^{*}$ & -0.0264 & $-0.0459^{* *}$ & -0.0123 & -0.0318 \\
\hline & 0.0350 & 0.0335 & 0.0410 & 0.0213 & 0.0157 & 0.0247 \\
\hline \multirow[t]{2}{*}{ G- membership } & $0.0704^{* *}$ & $-0.0563^{*}$ & $0.1456^{* * *}$ & $-0.0347^{* *}$ & -0.0091 & 0.0107 \\
\hline & 0.0335 & 0.0367 & 0.0413 & 0.0233 & 0.0174 & 0.0258 \\
\hline \multirow[t]{2}{*}{ SWC_trained } & $-0.0643^{*}$ & -0.0093 & $0.1185^{* *}$ & -0.0128 & $-0.0478^{* *}$ & $0.0910^{* * *}$ \\
\hline & 0.0376 & 0.0404 & 0.0469 & 0.0235 & 0.0230 & 0.0264 \\
\hline \multirow[t]{2}{*}{ SNRM_traine } & 0.0091 & 0.0210 & $0.1575^{* * *}$ & $-0.0504^{* *}$ & 0.0194 & $-0.1334^{* * *}$ \\
\hline & 0.0346 & 0.0375 & 0.0448 & 0.0254 & 0.0160 & 0.0324 \\
\hline $\begin{array}{r}\text { Number o } \\
\text { Wald ch } \\
\text { Pseudo } \\
\text { Log pseudo } 1 \\
\end{array}$ & $\begin{array}{l}\text { Obs. } \\
91) \\
2 \\
\text { elihood }\end{array}$ & $\begin{array}{c}909 \\
918.10^{* * *} \\
0.2884 \\
-1132.645 \\
\end{array}$ & & & & \\
\hline
\end{tabular}

$* * *, * *$, and $*$ indicate significance level at $1 \%, 5 \%$, and $10 \%$, and (A0B0P0) is stand for base category $(\mathrm{i}=1)$ in the MNL

An increase in a household's plot size by one unit, increased the likelihood of practicing the $\mathrm{A}_{1} \mathrm{~B}_{0} \mathrm{P}_{1}$ package by $4 \%$. Large farm owners were closer to perceiving soil 
erosion problems and thus highly adopt physical conservation measures (Anim, 1999; Fikru, 2009; Mekuriaw et al., 2018; Moges and Taye, 2017; Nkomoki et al., 2018; Wekesa et al., 2018). Crop income is another important variable (a proxy of household food security status) for SIP adoption. A unit change in the amount of income is associated with a higher likelihood of adopting complete SIP packages $\left(\mathrm{A}_{1} \mathrm{~B}_{1} \mathrm{P}_{1}\right)$ by $43.42 \%$, at $1 \%$ significance level. However, it was also negatively associated with other combinations. The change in productivity due to SWC practices, especially from the physical structure, has a long-term effect. Wolka et al. (2018) confirmed that short-term low benefit from conservation practices demotivates farmers' interest in adopting the introduced SWC measures. Household off-farm participation was positively associated with $\left(\mathrm{A}_{0} \mathrm{~B}_{1} \mathrm{P}_{1}\right)$, while negatively associated with the Agronomic-Physical combination $\left(\mathrm{A}_{1} \mathrm{~B}_{0} \mathrm{P}_{1}\right)$. Since building physical structures is a labor-intensive practice, a household that frequently engages in off-farm employment wants to combine physical structures with others like a tree and supportive grass structures.

Information has played a vital role in driving farmers participation in the plot-level sustainable intensification decision process. The more a farmer has contact with agricultural extension workers, the higher the probability of adopting the $\mathrm{A}_{1} \mathrm{~B}_{1} \mathrm{P}_{0}$. Moreover, farmers' access to SWC, and SNRM related training showed positive association, and statistically significant with complete package $\left(\mathrm{A}_{1} \mathrm{~B}_{1} \mathrm{P}_{1}\right)$ and AgroPhysical $\left(\mathrm{A}_{1} \mathrm{~B}_{0} \mathrm{P}_{1}\right)$ choices. In essence, building a physical conservation structure demands technical skill and knowledge-intensive with regard to structure depth, width, and length design (Wolka et al., 2018). Similarly, main road access positively influenced SIP usage by farmers, and increased the probability of applying AgroPhysical measures $\left(\mathrm{A}_{1} \mathrm{~B}_{0} \mathrm{P}_{1}\right)$ by $9.6 \%$.

The rural network farmer members were 7 and $14.6 \%$ more likely to adopt $\mathrm{A}_{1} \mathrm{~B}_{1} \mathrm{P}_{0}$ and $\mathrm{A}_{1} \mathrm{~B}_{1} \mathrm{P}_{1}$ practices, respectively. This estimation result was consistent with a report by Kassie et al. (2013). Similarly, HH heads with access to credit were more likely to practice the Agro-Biological measures $\left(\mathrm{A}_{1} \mathrm{~B}_{1} \mathrm{P}_{0}\right)$, but less likely to apply Bio-Physical $\left(\mathrm{A}_{0} \mathrm{~B}_{1} \mathrm{P}_{1}\right)$ and Agronomic $\left(\mathrm{A}_{1} \mathrm{~B}_{0} \mathrm{P}_{0}\right)$ practices. The farmers preferred to expend borrowed money on other short respond business. Nkomoki et al. (2018) and Kpadonou et al. (2017) concurred with the negative influence of credit on SAP adoption.

\section{Impacts of SIPs adoption on smallholder food security}

In this section we used a joint analysis framework of SIP adoption average treatment effect on household food security in two ways. First, we compared the overall adoption effect between adopter and non-adopter groups. Second, we estimated a separate analysis of six SIP package choices' effect on the outcome variable to gain a better understanding of package combination.

\section{Overall SIP adoption impact on food security}

Table 7 illustrates the causal effect estimation result of SIP adoption on smallholders' food security. We compared changes in food security status among SIP adopters under the actual case and counterfactual (if not adopt) any SIP technology. ATT and ATU in table represent the average treatment effect on the treated and untreated conditions, respectively. ATE Diff column explains the net effect change on the outcome variable. It is calculated by controlling for the effect of several covariates, 
and the selection bias stemming problem, which comes from unobserved and observed conditions.

All food security indicator results showed that SIP adoption had a positive and significant effect, and adopters highly benefited compared to their counterparts in ranges of $1 \%$ significance level. SIP adopters were 55\% more food secure, had 51\% higher access to clean water and sanitation, and consumed at least one more dietary food item daily compared to non SIP adopters. Particularly, for nutritional dietary food access estimation (HDD), adoption would be advantageous and significant for both adopters and non-adopters, although adopter households would benefit the most. The majority of SIP adopters were better-off and exhibited higher dietary food intake compared to non SIP adopters. Likewise, adopting SIP technology ensured the household food availability (SAFS) throughout the year and improve the utilization of pure water and sanitation (WASH) facilities. Weight change was in agreement with results described by Coulibaly et al. (2017) and Kassie et al. (2015b).

In line with our result, other scholars have independently confirmed the positive effect of SIP adoption on the crop productivity and smallholders food security improvement. Kassie et al. (2015b) observed maize productivity increment following SIP adoption in Malawi, and Wekesa et al. (2018) investigated the positive association of Climate Smart Agriculture (CSA) and food security in Kenya. Similarly, Nkomoki et al. (2018) conducted a study on Sustainable Agricultural Practice (SAP) and food security in Zambia; where as Wolka et al. (2018) and Adgo et al. (2013) demonstrated that SAP and SWC adoption positively contributed to crop productivity and food security improvement for smallholders in Ethiopia.

Table 7. ATET of SIPs intervention on food security: endogenous switching regression estimation

\begin{tabular}{|c|c|c|c|c|}
\hline \multirow{2}{*}{ Treatment effect } & \multirow{2}{*}{ Outcome variable } & \multicolumn{2}{|c|}{ SIP decision stage } & \multirow{2}{*}{ ATE Diff } \\
\hline & & Adopters & Non-adopters & \\
\hline ATT & \multirow[t]{2}{*}{ HDD } & 6.86 & 5.62 & $1.24(0.068)^{* * *}$ \\
\hline ATU & & 4.23 & 3.74 & $0.49(0.080)^{* * *}$ \\
\hline ATT & \multirow[t]{2}{*}{ SAFS } & 0.62 & 0.07 & $0.55(0.025)^{* * *}$ \\
\hline ATU & & 0.16 & 0.55 & $-0.39(0.023)^{* * *}$ \\
\hline ATT & \multirow[t]{2}{*}{ WASH } & 0.55 & 0.04 & $0.51(0.026)^{* * *}$ \\
\hline \multirow[t]{4}{*}{ ATU } & & 0.15 & 0.57 & $-0.41(0.015)^{* * *}$ \\
\hline & \multicolumn{4}{|c|}{ Outcome variable spearman correlation matrix } \\
\hline & \multicolumn{2}{|c|}{$H D D$} & \multicolumn{2}{|l|}{$\begin{array}{l}\text { ation matrix } \\
S A F S\end{array}$} \\
\hline & $\begin{array}{c}H D D \\
\text { SAFS }\end{array}$ & $\begin{array}{c}1.000 \\
0.492^{* * *} \\
0.602^{* * *}\end{array}$ & \multicolumn{2}{|l|}{$\begin{array}{r}1.000 \\
0.981^{* * *}\end{array}$} \\
\hline
\end{tabular}

Standard errors in parentheses and $* * *, * *$, and * indicate significance level at $1 \%, 5 \%$, and $10 \%$

\section{Specific SIP package choice average treatment effect on food security}

Table 8 presents the treatment effect of food security indicators (HDD, SAFS, and WASH) from each combination of SIP choice under actual and counterfactual cases. A household that practices $\mathrm{A}_{1} \mathrm{~B}_{1} \mathrm{P}_{1}$ packages benefits from dietary food consumption and has pure water access under the actual and counterfactual condition. Agro-Biological 
package $\mathrm{A}_{1} \mathrm{~B}_{1} \mathrm{P}_{0}$ users would be better off to adopt, because HDD and SAFS measures had a significant ATT value at $1 \%$ significance level. Biophysical $\left(\mathrm{A}_{0} \mathrm{~B}_{1} \mathrm{P}_{1}\right)$ strategies integration also had a significant and positive contribution to food security through HDD and WASH improvements. The households that practiced the agro-physical structure combination $\left(\mathrm{A}_{1} \mathrm{~B}_{0} \mathrm{P}_{1}\right)$ were better off in the non-usage (ATU) scenarios suggesting that the household had other better combination available.

The appropriateness of SIP technologies practiced by a farmer was of profound importance in the context of changes in food security status. Overall, average effect estimation confirmed that a household that practiced $\mathrm{A}_{1} \mathrm{~B}_{1} \mathrm{P}_{0}, \mathrm{~A}_{1} \mathrm{~B}_{1} \mathrm{P}_{1}$, and $\mathrm{A}_{0} \mathrm{~B}_{1} \mathrm{P}_{1}$ packages substantially improved its food security status compared to its counterparts. In contrast, $\mathrm{A}_{0} \mathrm{~B}_{1} \mathrm{P}_{0}, \mathrm{~A}_{1} \mathrm{~B}_{0} \mathrm{P}_{0}$ and $\mathrm{A}_{1} \mathrm{~B}_{0} \mathrm{P}_{1}$ package usage had less contribution to reducing food insecurity compared to other strategies, while better than a scenario had they not adopted. The above comparison shows that mutually inclusive multiple SIP adoptions had a substantial impact on food security improvement compared to practicing individual agronomic or physical structure packages (Kpadonou et al., 2017)

Planting multi-purpose trees with physical structure would increase crop productivity through recycling soil nutrients as well as benefit farmers through generating diversified income. The benefits include forage for the animal (Amare et al., 2014), fruits, fuelwood, and immediate income (Mbow et al., 2014). Our findings on combined SIP adoption benefit were in accordance with other findings from Ethiopia reported by Sinore et al. (2018) and Wolka et al. (2018) from the south, Mekuriaw et al. (2018) and Amare et al. (2014) and Asfaw and Neka (2017) from the north.

Table 8. The average treatment effect of sustainable intensification practice choice on food security: Endogenous switching regression estimation

\begin{tabular}{|c|c|c|c|c|c|c|c|c|c|c|}
\hline \multirow{2}{*}{$\begin{array}{c}\text { Treatment } \\
\text { effect }\end{array}$} & \multirow[b]{2}{*}{ SIP choice } & \multicolumn{2}{|c|}{ HDD } & \multirow[b]{2}{*}{ ATE Diff } & \multicolumn{2}{|c|}{ SAFS } & \multirow[b]{2}{*}{ ATE Diff } & \multicolumn{2}{|c|}{ WASH } & \multirow[b]{2}{*}{ ATE Diff } \\
\hline & & $\begin{array}{c}\text { To } \\
\text { participate }\end{array}$ & $\begin{array}{c}\text { Not to } \\
\text { participate }\end{array}$ & & $\begin{array}{c}\text { To } \\
\text { participate }\end{array}$ & $\begin{array}{c}\text { Not to } \\
\text { participate }\end{array}$ & & $\begin{array}{c}\text { To } \\
\text { participate }\end{array}$ & $\begin{array}{c}\text { Not to } \\
\text { participate }\end{array}$ & \\
\hline ATT & $\mathrm{A}_{1} \mathrm{~B}_{1} \mathrm{P}_{1}$ & $7.46(0.06)$ & $5.31(0.05)$ & $2.15(0.08)^{* * * *}$ & $0.75(0.01)$ & $0.36(0.01)$ & $0.38(0.02)^{* * *}$ & $0.67(0.00)$ & $0.63(0.00)$ & $0.04(0.00)^{* * *}$ \\
\hline ATU & & $6.65(0.06)$ & $5.91(0.04)$ & $0.74(0.07)^{* * *}$ & $0.75(0.01)$ & $0.41(0.01)$ & $0.34(0.01)^{* *}$ & $0.41(0.00)$ & $0.42(0.00)$ & $-0.01(0.00)$ \\
\hline ATT & $\mathrm{A}_{1} \mathrm{~B}_{1} \mathrm{P}_{0}$ & $6.83(0.07)$ & $5.26(0.05)$ & $1.57(0.12)^{* * *}$ & $0.38(0.01)$ & $0.04(0.01)$ & $0.34(0.02)^{* * *}$ & $0.36(0.00)$ & $0.38(0.02)$ & $-0.02(0.01)$ \\
\hline ATU & & $5.15(0.06)$ & $5.66(0.04)$ & $-0.50(0.11)$ & $0.43(0.01)$ & $0.42(0.01)$ & $0.01(0.02)^{*}$ & $0.44(0.03)$ & $0.46(0.00)$ & $-0.02(0.02)$ \\
\hline ATT & $\mathrm{A}_{0} \mathrm{~B}_{1} \mathrm{P}_{1}$ & $6.13(0.06)$ & $5.06(0.04)$ & $1.07(0.09)^{* * *}$ & $0.41(0.02)$ & $0.38(0.01)$ & $0.03(0.02)^{* *}$ & $0.33(0.00)$ & $0.28(0.02)$ & $0.05(0.00)^{* * *}$ \\
\hline ATU & & $4.42(0.07)$ & $5.02(0.04)$ & $-0.60(0.11)$ & $0.47(0.00)$ & $0.48(0.05)$ & $-0.01(0.02)$ & $0.14(0.03)$ & $0.59(0.00)$ & $-0.44(0.02)$ \\
\hline ATT & $\mathrm{A}_{1} \mathrm{~B}_{0} \mathrm{P}_{1}$ & $5.09(0.08)$ & $5.08(0.04)$ & $0.01(0.06)$ & $0.54(0.03)$ & $0.53(0.01)$ & $0.01(0.03)$ & $0.48(0.03)$ & $0.36(0.01)$ & $0.12(0.03)^{* * *}$ \\
\hline ATU & & $6.17(0.12)$ & $5.89(0.05)$ & $0.28(0.14)^{* *}$ & $0.56(0.03)$ & $0.46(0.01)$ & $0.11(0.03)^{* * *}$ & $0.57(0.05)$ & $0.56(0.00)$ & $0.01(0.02)$ \\
\hline ATT & $\mathrm{A}_{1} \mathrm{~B}_{0} \mathrm{P}_{0}$ & $5.65(0.06)$ & $5.91(0.04)$ & $0.26(0.05)^{* * *}$ & $0.29(0.02)$ & $0.31(0.01)$ & $-0.20(0.01)$ & $0.38(0.01)$ & $0.36(0.02)$ & $0.02(0.02)$ \\
\hline ATU & & $4.03(0.03)$ & $4.41(0.04)$ & $-0.38(0.10)$ & $0.60(0.04)$ & $0.34(0.01)$ & $0.24(0.03)^{* * * *}$ & $0.23(0.02)$ & $0.27(0.01)$ & $0.04(0.01)^{*}$ \\
\hline ATT & $\mathrm{A}_{0} \mathrm{~B}_{1} \mathrm{P}_{0}$ & $5.31(0.07)$ & $5.68(0.05)$ & $-0.37(0.12)^{* * *}$ & $0.21(0.05)$ & $0.25(0.01)$ & $-0.04(0.02)$ & $0.41(0.00)$ & $0.42(0.00)$ & $-0.01(0.00)$ \\
\hline ATU & & $5.43(0.06)$ & $5.52(0.04)$ & $-0.09(0.10)$ & $0.64(0.04)$ & $0.37(0.01)$ & $0.27(0.03)^{* * * *}$ & $0.53(0.00)$ & $0.47(0.00)$ & $0.06(0.01)^{* *}$ \\
\hline
\end{tabular}

Standard errors in parentheses and ${ }^{* * *},{ }^{* *}$, and ${ }^{*}$ indicate significance level at $1 \%, 5 \%$, and $10 \%$, and $\left(\mathrm{A}_{0} \mathrm{~B}_{0} \mathrm{P}_{0}\right)$ is stand for base category $(\mathrm{i}=1)$ as non-adopters from alternative packages

\section{Conclusion and policy implication}

Sustainable agricultural discourse comprises food security and SIP, which focus on increasing productivity and improving environmental protection. In Ethiopia, where frequent drought, poverty, and food shortages occur, environmental degradation represents a severe challenge. Therefore, SIP adoption must be considered as a policy approach, due to the fact that farmers in low-income countries are highly dependent on agriculture to increase farm productivity and reduce food deficiency risks. 
In this study, we investigated the factors that influence the adoption of SIP and their impact on food security using cross-sectional data from 909 farm households in Ethiopia. The study addresses three dimensions of food security- availability, access, and utilization. Principal component analysis (PCA) was employed first for variable reduction. Afterwards, we applied a two-stage multinomial endogenous switching regression model to obtain consistent and efficient estimates. Our study reveals that SIP adoption is positively correlated with households' food security. Adopting at least one SIPs package had a positive effect on food security improvement compared to not adopting a practice. Ultimately, households that adopt all three packages $\left(\mathrm{A}_{1} \mathrm{~B}_{1} \mathrm{P}_{1}\right)$ are the best in all three food security dimensions. Combining of the physical structure with biological measures $\left(\mathrm{A}_{0} \mathrm{~B}_{1} \mathrm{P}_{1}\right)$, and integrating agronomic with biological measures $\left(\mathrm{A}_{1} \mathrm{~B}_{1} \mathrm{P}_{0}\right)$ proved to be the best strategies besides complete SIP adoption.

Furthermore, the findings reveal that a male-headed household is positively associated with the use of Agro-Biological $\left(\mathrm{A}_{1} \mathrm{~B}_{1} \mathrm{P}_{0}\right)$, than labor-intensive AgroPhysical $\left(\mathrm{A}_{1} \mathrm{~B}_{0} \mathrm{P}_{1}\right)$ package. Again, formal education is required for adopting knowledge-intensive physical structures much more so than for agronomic practices, although large farm size owner households are more likely to practice the AgroPhysical (A1B0P1) package. A proxy crop income variable significantly determined complete package adoption, and a unit change income improved the $\left(\mathrm{A}_{1} \mathrm{~B}_{1} \mathrm{P}_{1}\right)$ adoption by $43.42 \%$. A household off-farm participation increases adoption of the Biophysical $\left(\mathrm{A}_{0} \mathrm{~B}_{1} \mathrm{P}_{1}\right)$ package by $6 \%$. Other information and training related variables such as farmers contact to extension worker, training participation on SWC and SNRM, access to roads and farmers' participation in the rural network are positively associated with biophysical and agro-biological adoption compared to the agro-physical and individual package.

Therefore, our findings strongly indicate that SIP adoption has the potential to reduce food insecurities and poverty among smallholder farmers in fixed cropping areas. Regarding SIP adoption campaign and sensitization program for development partners and government, we recommend the adoption of SIP combinations such as Bio-Physical $\left(\mathrm{A}_{0} \mathrm{~B}_{1} \mathrm{P}_{1}\right)$, and Agro-Biological $\left(\mathrm{A}_{1} \mathrm{~B}_{1} \mathrm{P}_{0}\right)$ for integration as a priority policy approach, in addition to the complete package $\left(\mathrm{A}_{1} \mathrm{~B}_{1} \mathrm{P}_{1}\right)$.

Finally, our study is not without limitations, with time being the major limitation in that we used a single round survey of one-year response, which might affect the quality of our impact analysis. Exclusion of plot-level SIP and agro-ecological information is another limitation. However, the sample size, number of outcome variable used, and models applied for consistency and robustness can minimize these limitation effects. Other follow-up studies are needed to support our findings in other settings, with better long-period data and methodologies to validate the analysis.

Acknowledgements. The authors acknowledge the research fund sponsorship by "Social Science Foundation for Universities in Jiangsu, China, grant number 2017ZDIXM096", "National Social Science Foundation, China, grant number 13\&zd160" and "the Priority Academic Program Development of Jiangsu Higher Education Institutions (PAPD) Project”. Also, we thank the reviewers for the useful reviews which have significantly improved the quality of the paper. 


\section{REFERENCES}

[1] Abdul-Rahim, A., Sun, C., Noraida, A. (2018): The impact of soil and water conservation on agricultural economic growth and rural poverty reduction in China. - Sustainability 10(12): 4444.

[2] Abdulai, A., Huffman, W. (2014): The adoption and impact of soil and water conservation technology: an endogenous switching regression application. - Land Economics 90(1): 26-43.

[3] Adgo, E., Teshome, A., Mati, B. (2013): Impacts of long-term soil and water conservation on agricultural productivity: the case of Anjenie watershed, Ethiopia. Agricultural Water Management 117: 55-61.

[4] Amare, T., Zegeye, A. D., Yitaferu, B., Steenhuis, T. S., Hurni, H., Zeleke, G. (2014): Combined effect of soil bund with biological soil and water conservation measures in the northwestern Ethiopian highlands. - Ecohydrology \& Hydrobiology 14(3): 192-199.

[5] Anderson, S., Elisabeth, F. (2015): USAID Office of Food for Peace Food Security Country Framework for Ethiopia FY 2016-FY 2020. - Food Economy Group, Washington, DC.

[6] Anim, F. D. (1999): A note on the adoption of soil conservation measures in the Northern Province of South Africa. - Journal of Agricultural Economics 50(2): 336-345.

[7] Asfaw, D., Neka, M. (2017): Factors affecting adoption of soil and water conservation practices: the case of Wereillu Woreda (District), South Wollo Zone, Amhara Region, Ethiopia. - International Soil and Water Conservation Research 5(4): 273-279.

[8] Bourguignon, F., Fournier, M., Gurgand, M. (2007): Selection bias corrections based on the multinomial logit model: Monte Carlo comparisons. - Journal of Economic Surveys 21(1): 174-205.

[9] Branca, G., Lipper, L., McCarthy, N., Jolejole, M. C. (2013): Food security, climate change, and sustainable land management. A review. - Agronomy for Sustainable Development 33(4): 635-650.

[10] Chatterjee, S., Goswami, R., Bandopadhyay, P. (2015): Methodology of identification and characterization of farming systems in irrigated agriculture: case study in west Bengal State of India. - Journal of Agricultural Science and Technology 17(5): 11271140 .

[11] Coulibaly, J. Y., Chiputwa, B., Nakelse, T., Kundhlande, G. (2017): Adoption of agroforestry and the impact on household food security among farmers in Malawi. Agricultural Systems 155: 52-69.

[12] Dejene, A. (2003): Integrated natural resources management to enhance food security. The case for community-based approaches in Ethiopia. Environment and natural resources working paper 16.

[13] Di Falco, S., Veronesi, M., Yesuf, M. (2011): Does adaptation to climate change provide food security? A micro-perspective from Ethiopia. - American Journal of Agricultural Economics 93(3): 829-846.

[14] Ecker, O. (2018): Agricultural transformation and food and nutrition security in Ghana: Does farm production diversity (still) matter for household dietary diversity? - Food Policy 79: 271-282.

[15] Emana, B. (2010): Market Assessment and Value Chain Analysis in Benishangul Gumuz Regional State, Ethiopia. - SID-Consult-Support Integrated Development, Addis Ababa, Ethiopia.

[16] FAO (2016): The State of Food and Agriculture-Climate Change, Agriculture and Food Security. - Food and Agriculture Organization of the United Nations, Rome.

[17] Fikru, A. (2009): Assessment of adoption of soil and water conservation practice in Koga watershed, highlands of Ethiopia. - Unpublished Master Thesis. Cornell University, Faculty of Graduate School, Cornell. 
[18] Goswami, R., Biswas, M. S., Basu, D. (2012): Validation of participatory farming situation identification: a case of rainfed rice cultivation in selected area of West Bengal, India. - Indian Journal of Traditional Knowledge 11(3): 471-479.

[19] Josephson, A. L., Ricker-Gilbert, J., Florax, R. J. (2014): How does population density influence agricultural intensification and productivity? Evidence from Ethiopia. - Food Policy 48: 142-152.

[20] Kaiser, H. F. (1958): The varimax criterion for analytic rotation in factor analysis. Psychometrika 23(3): 187-200.

[21] Kassie, M., Jaleta, M., Shiferaw, B., Mmbando, F., Mekuria, M. (2013): Adoption of interrelated sustainable agricultural practices in smallholder systems: evidence from rural Tanzania. - Technological Forecasting and Social Change 80(3): 525-540.

[22] Kassie, M., Teklewold, H., Jaleta, M., Marenya, P., Erenstein, O. (2015a): Understanding the adoption of a portfolio of sustainable intensification practices in eastern and southern Africa. - Land Use Policy 42: 400-411.

[23] Kassie, M., Teklewold, H., Marenya, P., Jaleta, M., Erenstein, O. (2015b): Production risks and food security under alternative technology choices in Malawi: application of a multinomial endogenous switching regression. - Journal of Agricultural Economics 66(3): 640-659.

[24] Kim, J., Park, H., Chun, J., Li, S. (2018): Adaptation strategies under climate change for sustainable agricultural productivity in Cambodia. - Sustainability 10(12): 4537.

[25] Kipkoech Anderson, K., Emmanuel, T., Bangali Solomon, F. (2015): State of Knowledge on CSA in Africa. Case Studies from Ethiopia, Kenya and Uganda. - Forum for Agricultural Research in Africa, Accra, Ghana ISBN.

[26] Kpadonou, R. A. B., Owiyo, T., Barbier, B., Denton, F., Rutabingwa, F., Kiema, A. (2017): Advancing climate-smart-agriculture in developing drylands: joint analysis of the adoption of multiple on-farm soil and water conservation technologies in West African Sahel. - Land Use Policy 61: 196-207.

[27] Lee, L.-F. (1982): Some approaches to the correction of selectivity bias. - The Review of Economic Studies 49(3): 355-372.

[28] Mabiso, A., Cunguara, B., Benfica, R. (2014): Food (in)security and its drivers: insights from trends and opportunities in rural Mozambique. - Food Security 6(5): 649-670.

[29] Maxwell, D., Vaitla, B., Coates, J. (2014): How do indicators of household food insecurity measure up? An empirical comparison from Ethiopia. - Food Policy 47: 107116.

[30] Mbow, C., Van Noordwijk, M., Luedeling, E., Neufeldt, H., Minang, P. A., Kowero, G. (2014): Agroforestry solutions to address food security and climate change challenges in Africa. - Current Opinion in Environmental Sustainability 6: 61-67.

[31] McDonald, C. M., McLean, J., Kroeun, H., Talukder, A., Lynd, L. D., Green, T. J. (2015): Correlates of household food insecurity and low dietary diversity in rural Cambodia. - Asia Pacific Journal of Clinical nutrition 24(4): 720-730.

[32] Mekuriaw, A., Heinimann, A., Zeleke, G., Hurni, H. (2018): Factors influencing the adoption of physical soil and water conservation practices in the Ethiopian highlands. International Soil and Water Conservation Research 6(1): 23-30.

[33] Moges, D. M., Taye, A. A. (2017): Determinants of farmers' perception to invest in soil and water conservation technologies in the North-Western Highlands of Ethiopia. International Soil and Water Conservation Research 5(1): 56-61.

[34] Moroda, G. T., Tolossa, D., Semie, N. (2018): Food insecurity of rural households in Boset district of Ethiopia: a suite of indicators analysis. - Agriculture \& Food Security 7(1): 65 .

[35] Nkomoki, W., Bavorová, M., Banout, J. (2018): Adoption of sustainable agricultural practices and food security threats: effects of land tenure in Zambia. - Land Use Policy 78: $532-538$. 
[36] Pérez-Escamilla, R., Gubert, M. B., Rogers, B., Hromi-Fiedler, A. (2017): Food security measurement and governance: assessment of the usefulness of diverse food insecurity indicators for policy makers. - Global Food Security 14: 96-104.

[37] Petteri Vuorinen, M. T., Jorn Laxen (2016): Study of causes of deforestation and forest degradation in Ethiopia and the identification and prioritization of strategic options to address those final reports. - Ministry of Environment, Forest and Climate Change, The Federal Democratic Republic of Ethiopia, Addis Ababa.

[38] Pinstrup-Andersen, P. (2009): Food security: definition and measurement. - Food Security 1(1): 5-7.

[39] Shiferaw, B., Kassie, M., Jaleta, M., Yirga, C. (2014): Adoption of improved wheat varieties and impacts on household food security in Ethiopia. - Food Policy 44: 272-284.

[40] Sinore, T., Kissi, E., Aticho, A. (2018): The effects of biological soil conservation practices and community perception toward these practices in the Lemo District of Southern Ethiopia. - International Soil and Water Conservation Research 6(2): 123-130.

[41] Teklemariam, D., Azadi, H., Nyssen, J., Haile, M., Witlox, F. (2016): How sustainable is transnational farmland acquisition in Ethiopia? Lessons learned from the BenishangulGumuz Region. - Sustainability 8(3): 213.

[42] Tiwari, K. R., Sitaula, B. K., Nyborg, I. L., Paudel, G. S. (2008): Determinants of farmers' adoption of improved soil conservation technology in a middle mountain watershed of central Nepal. - Environmental Management 42(2): 210-222.

[43] WB Dataset (2018): Agriculture \& Rural Development. - World Bank. https://data.worldbank.org/indicator. 12 December 2018.

[44] WBISPP (2005): A national strategy plan for the biomass sector. Available online: https://www.coursehero.com/file/32669878/ddfd-midtermreportdoc/, The Federal Democratic Republic of Ethiopia, REDD+ Secretariat, Ministry of Environment and Forest Addis Ababa, Ethiopia (Accessed on 25 January, 2019).

[45] Wekesa, B. M., Ayuya, O. I., Lagat, J. K. (2018): Effect of climate-smart agricultural practices on household food security in smallholder production systems: micro-level evidence from Kenya. - Agriculture \& Food Security 7(1): 80.

[46] Wolka, K., Sterk, G., Biazin, B., Negash, M. (2018): Benefits, limitations and sustainability of soil and water conservation structures in Omo-Gibe basin, Southwest Ethiopia. - Land Use Policy 73: 1-10. 